\title{
Resistance against Fusarium graminearum and the relationship to $\beta$-glucan content in barley grains
}

\author{
Charlotte Martin • Torsten Schöneberg • Susanne Vogelgsang • Romina Morisoli • \\ Mario Bertossa • Brigitte Mauch-Mani • Fabio Mascher
}

Accepted: 21 May 2018 / Published online: 6 June 2018

(C) The Author(s) 2018

\begin{abstract}
Fusarium head blight (FHB) caused by $F u$ sarium graminearum (FG) is a destructive disease impacting barley worldwide. The disease reduces the grain yield and contaminates grains with mycotoxins, such as the trichothecene deoxynivalenol (DON). Although the infection mainly affects the grain yield, little is known about its impact on grain structural and biochemical properties. Yet, such information is instrumental to characterize the facets of resistance in the grains. After artificial inoculation of six barley cultivars with FG in a 2 years field test, different levels of symptoms on spikes, of colonisation of grains and of DON content were observed. The infections caused a reduction in grain weight and an average decrease of $10 \%$ of the $\beta$ glucan content in grains, indicating alterations of grain
\end{abstract}

Electronic supplementary material The online version of this article (https://doi.org/10.1007/s10658-018-1506-8) contains supplementary material, which is available to authorized users.

C. Martin · F. Mascher $(\bowtie)$

Agroscope, Plant Breeding and Genetic Ressources, 1260 Nyon, Switzerland

e-mail: fabio.mascher@agroscope.admin.ch

T. Schöneberg $\cdot$ S. Vogelgsang

Agroscope, Ecology of Noxious and Beneficial Organisms, 8046 Zürich, Switzerland

R. Morisoli · M. Bertossa

Agroscope, Ecology of Noxious and Beneficial Organisms, 6593 Cadenazzo, Switzerland

B. Mauch-Mani

Agroscope, Plant Protection South of the Alps, University of Neuchâtel, 2000 Neuchâtel, Switzerland filling, composition and structure. According to our results, we postulate the presence of two distinct resistance mechanisms in the grain, tolerance to grain filling despite infection as well as the inhibition of mycotoxin accumulation. Differently to wheat, in barley, type IV resistance (tolerance of the grain to infection) is directly linked with type III resistance (resistance against kernel infection). The resistance against toxin accumulation (named type $\mathrm{V}$ resistance in wheat) appeared to be independent to all other resistance types. Generally, the resistance was significantly influenced by the environment and by genotype $\mathrm{x}$ environment interactions explaining the generally weak stability of resistance in barley. Interestingly, a significant and inverse relationship between DON contamination and $\beta$-glucan content in grains suggests that high $\beta$-glucan content in grains contributes to type $\mathrm{V}$ resistance.

Key words Fusarium head blight · deoxynivalenol . resistance types $\cdot$ grain filling $\cdot$ health promoting compound

\section{Abbreviation \\ $\beta$-glucan 1,3:1,4- $\beta$-D-glucan}

\section{Introduction}

Fusarium head blight (FHB) of small grain cereals is caused by different species of the genus Fusarium. The disease is known in all cereal producing areas of the world. 
Besides yield losses, infections lead to accumulation of different mycotoxins in the grains and grain deformation, resulting in so called tombstones and reduced process quality (Häller Gärtner et al. 2008; Martin et al. 2017). FHB infections can cause significant economic losses along the entire value chain (McMullen et al. 1997). In temperate climates, Fusarium graminearum (FG) is a common pathogen of barley (Ioos et al. 2004; Nielsen et al. 2014) and the dominant species in barley, in Switzerland (Schöneberg et al. 2016). FHB development starts after primary infection when spores released from crop residues, transported by wind and rain, are deposited on florets (Bai and Shaner 2004). The infection takes place at anthesis and is favoured by high humidity conditions and temperatures between $16^{\circ} \mathrm{C}-20^{\circ} \mathrm{C}(\mathrm{Xu} 2003$; Brennan et al. 2005; Musa et al. 2007). Once established in the ear, the infection progresses throughout the spike, causing water-soaked appearance of the spikelets and progressive blighting. The pathogen interferes with grain development, leading to reduction of filling and changes in composition (McMullen et al. 1997; Bai and Shaner 2004; Oliveira et al. 2013). During the infection process, $F$. graminearum produces the mycotoxin deoxynivalenol (DON) that accumulates in grains. Fodder barley contaminated with DON can result in feed refusal, diarrhea, vomiting, and growth depression in farm animal (D'Mello et al. 1999; Dersjant-li et al. 2003). The contamination of barley grains for human consumption may also cause health problems, since mycotoxins remain in the final product (Kushiro 2008; Malachova et al. 2012). In Europe, contaminations with DON in cereal products are subject to strict regulations to guarantee food and feed safety. For barley and wheat, maximum limits in unprocessed cereals for human consumption are set to $1250 \mu \mathrm{g} . \mathrm{kg}^{-1}$ of DON set (European Commission Regulation (EC) No 1881/2006).

The cultivation of resistant varieties is the most sustainable and cost effective way to control yield losses and contamination with mycotoxins (Mascher et al. 2005). In wheat, FHB resistance involves a multitude of resistance mechanisms. Schroeder and Christensen (1963) first observed the resistance against the primary infection (called type I resistance) and the resistance impeding the spread of the infection throughout the spike (called type II resistance). Resistance types of the grain include: resistance against kernel infection (type III), tolerance to yield loss (type IV), resistance against the accumulation of trichothecenes mycotoxins in the grain (type $\mathrm{V}$ ) and also the resistance against the alteration of grain constituents (type
VI) (Mesterházy et al. 1999; Boutigny et al. 2008; Martin et al. 2017). In wheat, all these resistance types are interdependent, but independently inherited (Bai et al. 2000). The wealth of knowledge on FHB in wheat can only be partially applied to barley (Bai and Shaner 2004; Berger et al. 2014). In wheat, the mycotoxin DON is considered to be an essential virulence factor allowing the pathogen to invade the rachis and to overcome type II resistance (Maier et al. 2006). In barley, the fungus was observed to grow externally from one spikelet to another, without penetrating the rachis (Jansen et al. 2005); thus, DON appears to be redundant in the spread of the pathogen throughout the spike (Langevin et al. 2004). In barley, resistance evaluation should focus on type I resistance, since type II resistance appears to be strong. Concerning grains, differences in resistance to FHB and DON accumulation between spring barley genotypes have been reported (Buerstmayr et al. 2004). Moreover, significant effects of the genotype on yield loss and yield components were described by Chełkowski et al. (2000). Yet, the knowledge about the impact of FHB on barley grain structure, chemical composition and metabolism are far lower than in wheat grains (Foroud and Eudes 2009). Without this information, the underlying mechanisms of type III, IV, V and VI resistance cannot be accurately characterized.

Barley grains contain $\beta$-glucan, a soluble fibre which accumulates in the cell walls of the endosperm during maturation; $\beta$-glucan represents between 2 to $10 \%$ of the dry mass of the grain (Fincher 1975; Izydorczyk et al. 2000; Zhang et al. 2002; Wilson et al. 2012). High $\beta$-glucan content in grains is recommended for a healthy diet and health benefits as claimed by EFSA and US Food and Drug Administration FDA (European Food Safety Organisation 2011; FDA 1997; FDA 2005; Wood 2007). In barley grains, the biosynthesis of $\beta$ glucan depends on the availability of polysaccharides, in particular sucrose, and on an undisturbed metabolism of the cells (Becker et al. 1995). Hence, tracing the content in $\beta$-glucan of the grain after infection will help to understand the impact of the infection on the grain's biochemical composition and metabolism. $\beta$-glucan also possesses antioxidant activity (Kofuji et al. 2012). Antioxidant compounds are a recognized factor of the plant's defence system to cope with biotic aggressors (Lattanzio et al. 2006; Zhou et al. 2007). To date, the role of $\beta$-glucan against the infection by Fusarium pathogens remains to be investigated.

The aim of the current study was to investigate resistance elements of the barley grain against 
F. graminearum and the accumulation of deoxynivalenol. For this, we precisely characterized the outcome of $\mathrm{Fu}$ sarium infections on grains of barley. The experimental approach was based on the study of six winter barley varieties with and without artificial infection at six experimental field sites with distinct climatic conditions. In the field, disease incidence and severity were scored as indicators of spike resistance. After harvest, grains were examined for fungal infection, thousand kernel weight (TKW), and DON content, to respectively assess the grain resistance against Fusarium infection (type 3), deformation (type 4) and toxin contamination (type 5). The $\beta$-glucan content was determined to study the impact of FG infection on grain composition, structure and functioning. By this, the contribution of $\beta$-glucan in resistance of barley grains was also investigated.

\section{Materials and methods}

Plant material

Six winter barley genotypes, all registered varieties from different European breeders, have been studied in this experiment (Table 1). The set includes the 2 row variety "Cassia" and the hybrid variety "Hobbit". The variety "Waxyma", was specially bred for an elevated $\beta$-glucan content and is recommended for human consumption. The other varieties are generally used as animal feed, are popular in Switzerland and figure on the national recommended list (Courvoisier et al. 2017).

Fungal isolates and production of inoculum

Infections were carried out with a mix of three $F$. graminearum single conidia isolates from symptomatic barley spikes: FG 13170 (isolated in 2013, canton Fribourg), FG 13192 (2013, Basel-Land) and FG 13269
(2013, Graubünden). Strains were stored in a 1:1 water glycerol mix at $-80^{\circ} \mathrm{C}$. For mass production, strains were retrieved from deep freezing and cultured on Potato Dextrose Agar (PDA, BD Difco, Le Pont de Claix, France) for 1 week at $18^{\circ} \mathrm{C}$ with $12 \mathrm{~h} / 12 \mathrm{~h} \mathrm{UV}$ light and dark. Subsequently, two mycelial discs ( $5 \mathrm{~mm}$ diam.) from a well-grown colony were transferred to $100 \mathrm{~mL}$ of liquid V8-medium in a $250 \mathrm{ml}$ Erlenmeyer flask. The V8-medium consisted of a 1:5 mix of V8 juice (Campbell Soup Company, Camden, USA) and distilled water, amended with $2 \mathrm{~g}$ sodium carbonate per litre as a $\mathrm{pH}$ corrector $\left(\mathrm{pH}_{\text {media }}=8.5\right)$. Cultures were incubated for 7 days (d) at $24^{\circ} \mathrm{C}$ on a shaker at $200 \mathrm{rpm}$ in the dark, subsequently filtered through sterile cheesecloth and centrifuged at $4500 \mathrm{rpm}$ for $10 \mathrm{~min}$. The generated pellet was re-suspended in sterile distilled water and either directly used or stored at $-20{ }^{\circ} \mathrm{C}$.

Field tests and artificial inoculations

Field tests were conducted at four different locations across Switzerland: Changins (46 $\left.24^{\prime} 36^{\prime \prime} / 6^{\circ} 14^{\prime} 06^{\prime \prime}\right)$, Vouvry (4620'16"/653'28"), Reckenholz (47 $\left.16^{\prime} 30^{\prime \prime} / 8^{\circ} 26^{\prime} 45^{\prime \prime}\right)$, and Cadenazzo (46 $06^{\circ} 00^{\prime \prime} /$ $\left.8^{\circ} 57^{\prime} 00^{\prime \prime}\right)$. Field tests were carried out in 2014 in Changins and Vouvry and in 2014 and 2015 in Reckenholz and Cadenazzo. Information about weather conditions of the experimental sites is given in Table 2 .

The varieties were planted during the month of October in $1 \mathrm{~m}^{2}$ plots with 5 rows and $15 \mathrm{~cm}$ interline using a Seedmatic seeding machine (Hege Maschinen, Eging am See, Germany). According to the local habits, seed density was 350 seeds $\mathrm{m}^{-2}$ for all varieties. All trials at all sites passed winter without significant losses. At flowering, rows were well established, dense and without gaps.

Artificial inoculations took place when $50 \%$ of the plants of a plot were at mid anthesis (BBCH 65). Inoculum suspension was prepared from fresh cultures

Table 1 Winter barley varieties used in the experiments

\begin{tabular}{lllll}
\hline Varieties & Row type & Breeder & Year of registration & Country \\
\hline Cassia & 2 & KWS & 2010 & United Kingdom \\
Fridericus & 6 & KWS & 2006 & Germany \\
Hobbit (Hybrid) & 6 & Syngenta & 2009 & United Kingdom \\
Landi & 6 & Saatzucht Schmidt & 2002 & Germany \\
Semper & 6 & KWS & 2009 & Germany \\
Waxyma & 6 & Dieckmann Seeds & 2008 & Germany \\
\hline
\end{tabular}


Table 2 Average temperature, relative humidity, evapotranspiration and sum of precipitation at the six field sites between 15.05. (flowering stage) and 15.07. (grain maturity) in 2014 and between 15.05.and 15.07. in 2015

\begin{tabular}{lllll}
\hline & Temperature $\left({ }^{\circ} \mathrm{C}\right)$ & Precipitation $(\mathrm{mm})$ & Relative humidity $(\%)$ & Evapotranspiration $(\mathrm{mm})$ \\
\hline Changins (VD) 2014 & 17.1 & 201 & 68 & 3.1 \\
Vouvry (VS) 2014 & 16.9 & 221 & 73 & 2.2 \\
Reckenholz (ZH) 2014 & 16.8 & 208 & 70 & 2.9 \\
Reckenholz (ZH) 2015 & 18.1 & 161 & 69 & 3.2 \\
Cadenazzo (TI) 2014 & 18.9 & 410 & 70 & 2.3 \\
Cadenazzo (TI) 2015 & 20.8 & 279 & 68 & 2.9 \\
\hline
\end{tabular}

meteoswiss.ch/idaweb

Cantons: VD, Vaud; VS, Valais; $T I$, Ticino; $Z H$, Zurich

adjusted to $2 \times 10^{5}$ conidia. $\mathrm{ml}^{-1}$. Immediately before inoculation, equal proportions of liquid cultures from each of the three FG strains were mixed and $0.0125 \%$ of Tween ${ }^{\circledR}$ were added. Suspensions were applied with a hand-sprayer (Spray-Matic 1.25P, Birchmeier) until runoff. According to the weather conditions, the inoculated and control plots were irrigated to maintain humidity on the ears for at least $24 \mathrm{~h}$ to promote primary infection. A high pressure/low volume overhead mist irrigation system was used in Changins. In Vouvry, Cadenazzo and Reckenholz, water was sprayed manually with a backpack sprayer. The additional water supply was about $600 \mathrm{~L} \mathrm{ha}^{-1}$, at all sites, and did not increase the water balance significantly (Table 2). To ensure that the plants received an adequate quantity of conidia, a second inoculation took place 2 days later.

\section{Disease assessments on spikes}

At Cadenazzo, Changins, Reckenholz and Vouvry, disease severity and disease incidence on spikes were determined in both control and inoculated plots. For this, in each plot, 30 spikes were randomly chosen, labelled, and the total number of spikelets per spike was determined. Disease incidence was scored by counting the number of infected spikes among the 30 spikes. Disease severity was recorded by counting the number of infected spikelets on each of the 30 spikes and expressed as percentage of infected spikelets on the total number of spikelets on the 30 spikes. The assessments started with the observation of first symptoms, between $7-10 \mathrm{~d}$ after the last inoculation. Subsequently, the progressive blighting of spikelets was scored at 3-d intervals. At least three assessments were carried out in each plot.
Harvest and preparation of grain samples

In Changins, Vouvry and Reckenholz each field test plot was individually harvested at full maturity (BBCH 89). The trials at Cadenazzo could not be harvested, in both years, and grains could therefore not be analysed. In Reckenholz, a plot combine harvester (HEGE 140, Mähdreschwerke GmbH, Germany) was used. The airflow on the harvester was reduced to recover as much of the kernels as possible. In the other locations, all spikes were harvested by hand and collected in linen bags. The spikes were threshed with a laboratory thresher (Saatmeister, Kurt Pelz, Germany) and grains were cleaned using a vertical airflow (Baumann Saatzuchtbedarf, Germany) to remove dust and other debris. All grains were dried to $14 \%$ moisture and stored at $4{ }^{\circ} \mathrm{C}$. The grains harvested from one plot are treated as one sample. Sub-samples of $200 \mathrm{~g}$ were extracted after mixing each sample 3 times with a riffle divider (Schieritz \& Hauenstein AG, Arleheim, Switzerland)-

\section{Analyses of grains}

The proportion of grains colonised by the inoculated FG strains and other Fusarium spp pathogens was determined for all samples from artificially inoculated plots using the seed health test procedure described by Vogelgsang et al. 2008. For this, one hundred grains from each sample were surface sterilized and placed on PDA. After one week, the Fusarium species were identified according to the laboratory manual by Leslie and Summerell (2006).

The presence of naturally occurring Fusarium species was tested on three samples randomly chosen from non-inoculated plots from each field sites. 
The thousand kernel weight (TKW) (g) was measured with a MARVIN optical grain counter (Digital Seed Analyser, GTA Sensorik GmbH, Neubrandenburg, Germany) and a balance (Mettler PM2000, Mettler-Toledo, Greifensee, Switzerland). TKW was determined for all grain samples, from control and inoculated field plots.

The DON content in whole meal flour from inoculated plots was determined with the DON ELISA kit (Ridascreen ${ }^{\circledR}$ FAST DON, R-Biopharm AG, Darmstadt, Germany), according to the manufactures' instructions (LOD $<0.2 \mathrm{ppm}, \mathrm{LOQ}=0.2 \mathrm{ppm}$ ). Samples with high contamination were diluted 10 times in double distilled water. Whole meal flour was obtained by milling $10 \mathrm{~g}$ of sample with a sample mill (1093 Cyclotec Sample Mill, FOSS, Sweden), using a $1 \mathrm{~mm}$ screen. Samples were stored at $-20^{\circ} \mathrm{C}$ until further use. The DON content was measured in samples from inoculated plots, and in three samples randomly chosen from noninoculated plots from each field sites as a control. No DON was detected in the control samples.

The $\beta$-glucan content was also determined in whole meal flour (see above). For quantification, the Mixedlinkage $\beta$-glucan kit (Megazyme International Ireland Ltd., Wicklow, Ireland) was used. The streamlined method of mixed-linkage $\beta$-glucan in barley flour (ICC Standard Method No.166) was adapted to the laboratory facilities. As a negative control, the $\beta$ glucan content was measured in $0.1 \mathrm{~g}$ of dry FG mycelium from the strain FG13170. $\beta$-glucan content was measured in all samples, from inoculated and noninoculated plots.

Experimental set-up and statistical analysis

Field tests were conducted in a comparable way at all locations and included inoculated and non-inoculated treatments with three replicates arranged in a split-plot design. The treatments were the main plot whereas the different barley varieties were the sub-plots.

For each plot, data of disease incidence and severity were integrated by the number of observation days (number of days between inoculation and the last scoring), to obtain AUDPC (area under the disease pressure curve). AUDPC were then divided by the number of observation days, and defined relative AUDPC (AUDPCrel) as described elsewhere (Martin et al. 2017). This standardized average daily disease progress value allows the comparison of disease incidence and disease severity between the trial sites. Variation of
TKW due to the infection was calculated for each sample from inoculated plot as the difference with the average TKW of the three samples from non-infected plot of the same genotype from the same field test. All calculations were conducted on Microsoft ${ }^{\circledR}$ Excel 2013.

Statistical analyses were carried out using the statistical software R (R Core Team 2015). Results of AUDPCrel of disease severity in the six environments were illustrated with a biplot, using the average AUDPCrel of each genotype in each field test (R package "GGEBiplotGUI", version 1.0-9, Frutos et al. 2014). The data of DON content were square-root transformed to obtain normal distribution. The proportion of grains infected by FG (\%), the DON content (mg. $\mathrm{kg}^{-1}$ ) and the reduction of TKW (\%) were analysed with twofactor analyses of variances (ANOVA), with the trial site as main factor and the varieties as sub-factor. Pearson correlations were carried out to test the relationship between disease incidence, disease severity, the proportion of infected grains, the reduction of TKW and the DON content. To better understand kernel resistance and the role of $\beta$-glucan therein, a principal component analysis (R packages "FactoMineR", version 1.29, (Le et al. 2008)) was performed with the proportion of grains infected by FG, DON content and reduction of TKW as "factors" and one variety in one environment as "individuals". A hierarchical cluster analysis was carried out after the PCA to class individuals into distinct resistance clusters (R packages "factoextra", version 1.0.4, Kassambara and Mundt 2017). Variation of $\beta$ glucan content $(\%)$ in the dataset was analysed with a three-factors ANOVA, using, according to the experimental design, the "environment" as a main factor, the "treatment" indicating inoculation or control treatments as sub-factor and the different varieties as the smallest source of variation. Then $\beta$-glucan content (\%) in grains from inoculated plots were compared between the three resistance groups defined by the clustering on the PCA. All along the study, multiple comparisons were used based on Tukeys HSD (package "agricolae", De Mendiburu 2015).

\section{Results}

Symptoms on spikes

Symptoms on spikes were scored in all six field tests. AUDPCrel of severity are shown in Fig. 1. Symptoms 
were significantly more severe in Changins and Reckenholz in 2014 than in all other environments $(P<0.05)$. Only very weak symptoms were observed in Reckenholz 2015, and in Cadenazzo 2014. Symptoms in Cadenazzo 2015 and Vouvry 2014 were moderate. Pooled over all environments, the significantly highest $(P<0.05)$ disease severities on spikes were measured on "Hobbit" and the lowest on "Cassia" followed by "Waxyma" and "Semper" (Fig. 1). Results indicate that the varieties performed differently in the different environments. While "Hobbit" showed the highest disease severity in Changins 2014 and Cadenazzo 2015, it was not the most affected genotype in Reckenholz in 2014. The varieties "Fridericus" and "Waxyma" showed more symptoms in Vouvry and Reckenholz in 2014 in comparison with other environments. Yet, disease severity on "Semper" was very similar across the different environments. Disease incidence and disease severity were strongly correlated (Pearson coefficient $0.80, P<0.001$ ),

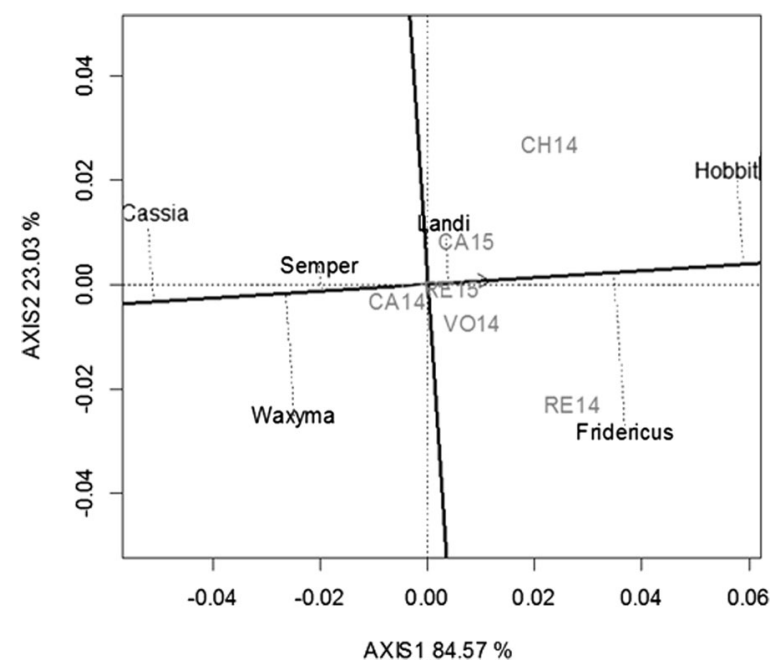

Fig. 1 Genotype main effect plus Genotype x Environment (GGE) biplot showing the average disease severity and its stability of the six barley genotypes over all six experimental sites. The plot has been obtained with R package GGEBiplotGUI with parameters "scalling=0" and "centering $=2$ " to illustrate both the six barley genotypes and the genotype $\mathrm{x}$ environment interactions. The parameter "singular value portioning" was set to $1(\mathrm{SVP}=1)$ scaling by the visualising the average points (variety / site) and the stability of the genotype. Position of the varieties along the horizontal axis indicates the average disease severity over all environments, with "Cassia" displaying weakest symptoms and "Hobbit" with strongest symptoms. The distance between variety and horizontal axis indicates the stability of disease severity. Short distances indicate high stability. CH14= Changins in 2014, in 2014, RE14= Reckenholz in 2014, VO14= Vouvry in 2014, CA14= Cadenazzo in 2014, CA15=Cadenazzo in 2015, RE15= Reckenholz in 2015 therefore only disease severity is shown here. All data of disease severity and incidence are presented in supplementary materials. In all field tests, none or very low symptoms were observed on non-inoculated plots.

Resistance of grains

\section{Proportion of grains colonised by Fusarium species}

FG was retrieved in all samples from inoculated plots, attesting to the success of the infection. Natural infections were observed in all samples. In samples from inoculated plots, less than $3 \%$ of the grains presented Microdochium nivale and less than $1 \%$ were colonised by F.poae or F.culmorum. In non-inoculated plots, less than $5 \%$ of grains were colonized by M.nivale and F.graminearum, and sporadically by F.poae and F.culmorum.

The proportion of grains colonized by FG with artificial inoculation on the six barley varieties in the four environments is displayed in Fig. 2a. The highest colonization was found in Reckenholz in 2015 (75\% of grains colonised) followed by Changins 2014, Reckenholz 2014 and Vouvry 2014 (22\%). Pooled over all environments, grains from "Fridericus" were significantly more colonised $(P<0.05)$ than grains of "Cassia" (60\% and 38\%, respectively) (Fig. 2a). Within the same environment, the proportion of colonised grains between varieties was rather similar, except for Changins in 2014 where "Waxyma" was only weakly colonised while the 5 other varieties, were strongly colonised (Fig. 2a). The impact of the environment on FG colonisation prevailed over the impact of the genotype (Table 3).

\section{Thousand kernel weight reductions}

A reduction of grain filling due to FG infection, measured by TKW comparisons was observed for all barley varieties in all environments, and ranged between $2 \%$ and $20 \%$ (Fig. 2b). The lowest reduction was measured in grains from "Cassia" with an average of $4 \%$ over all environments, whereas for the five other varieties, TKW reductions ranged between $8 \%$ and $11 \%$. The reduction of the TKW was also significantly influenced by the GxE interactions $(P<0.01)$ (Table 3). In particular, in Changins 2014, FG infection caused only weak reduction of TKW in grains from "Cassia" and "Fridericus" (respectively $2.5 \%$ and $6.9 \%$ of reduction), but elevated reductions of up to $14.5 \%$ in grains of "Hobbit". In 
Fig. 2 Proportion of Fusarium colonised grains (A), reduction of thousand kernel weight (TKW) (B), content of deoxynivalenol (DON) (C) for the six barley varieties in four environments. Error bars represent the standard error of the means. Different symbols indicate significantly different varieties in the same environment according to a Tukey-Test with $\alpha=0.05$
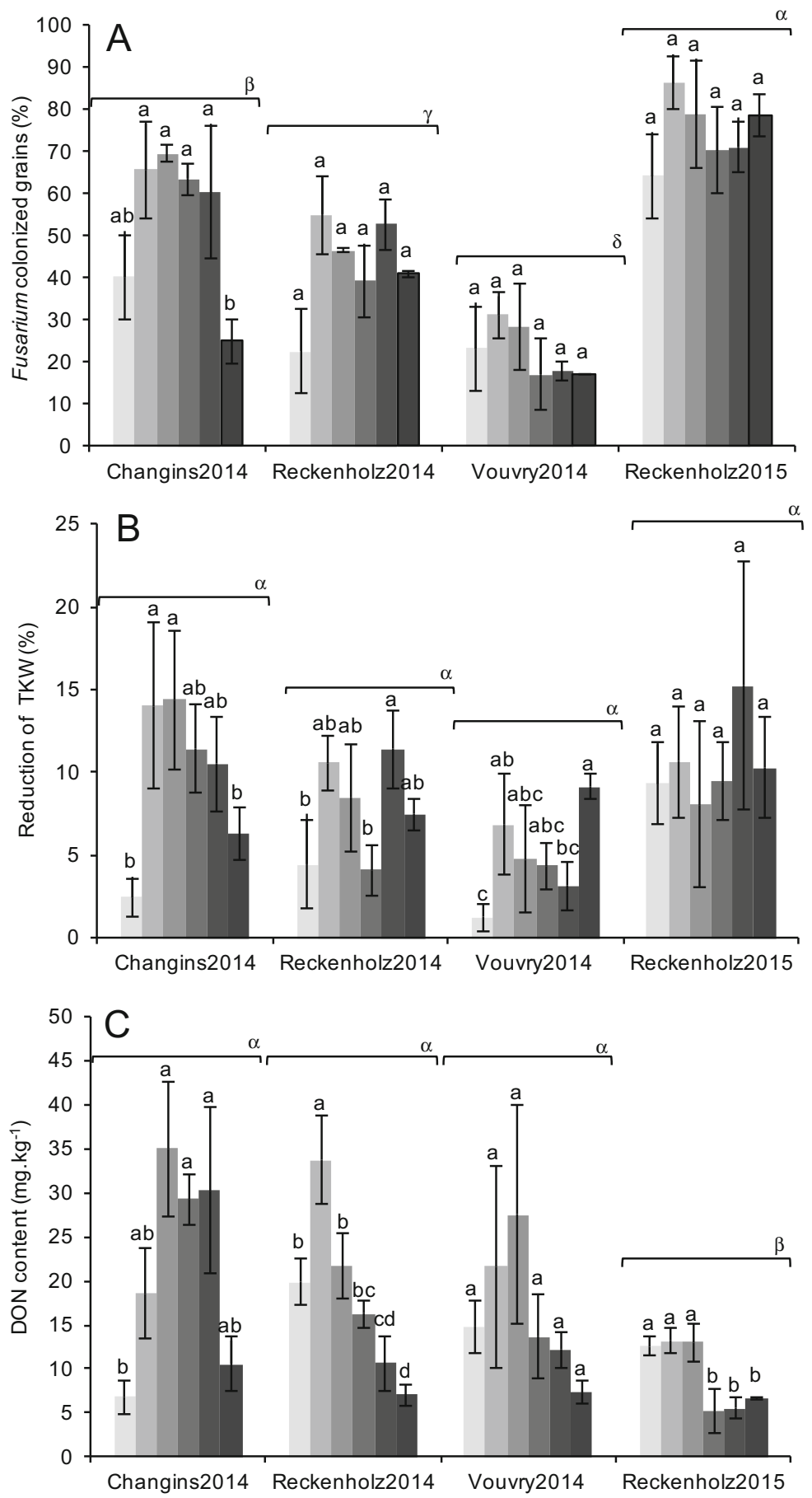

Barley varieties

Cassia Fridericus "Hobbit "Landi - Semper "Waxyma 
Table 3 Compositions of the variances of the proportion of colonised grains, the deoxynivalenol (DON) content and the reduction of thousand kernel weight (TKW) in function of the factors environment, genotype, and genotype $\mathrm{x}$ environment interaction

\begin{tabular}{|c|c|c|c|c|c|c|}
\hline \multirow[b]{2}{*}{ Source of variation } & \multicolumn{2}{|c|}{$\begin{array}{l}\text { Proportion of Fusarium graminearum } \\
\text { colonised grains }(\%)\end{array}$} & \multicolumn{2}{|c|}{ DON content $\left(\mathrm{mg} \mathrm{kg}^{-1}\right)$} & \multicolumn{2}{|c|}{ Reductions of TKW (\%) } \\
\hline & Sum of Square & Mean Square & Sum of Square & Mean Square & Sum of Square & Mean Square \\
\hline Environment & 26920 & $122.9 * * *$ & 21.4 & $7.2 *$ & 335.9 & 112.0 \\
\hline Error (A) & 916 & 153 & 4.8 & 0.8 & 307.5 & 51.2 \\
\hline Genotype & 4100 & $819.9 * * *$ & 31.1 & $6.2 * * *$ & 287.1 & $57.4 * * *$ \\
\hline Genotype $\mathrm{x}$ Environment & 4284 & $285.6 *$ & 30.4 & $2.0 * * *$ & 399.8 & $26.7 * *$ \\
\hline Error (B) & 4939 & 123.5 & 19.1 & 0.5 & 337.3 & 8.43 \\
\hline
\end{tabular}

Significance level: ***: $P<0.001, * *: P<0.01, *: P<0.05$

contrast, in Reckenholz 2015, no differences between varieties were observed (Fig. 2b).

\section{Accumulation of deoxynivalenol}

The mycotoxin DON was detected in all samples from inoculated plots. Contents varied from 5.2 to 49.4 $\mathrm{mg} \cdot \mathrm{kg}^{-1}$. The contamination was significantly lower in Reckenholz 2015 (on average $9.4 \mathrm{mg} \mathrm{kg}^{-1}$ ) than in all other environments (on average $18.1 \mathrm{mg} \mathrm{kg}^{-1}$ ) (Fig. 2c). Over the four environments, the highest average content was detected in grains from "Hobbit" (24.3 $\left.\mathrm{mg} \mathrm{kg}^{-1}\right)$, while grains from "Waxyma" were significantly $(P<0.05)$ less contaminated (on average $\left.7.9 \mathrm{mg} \mathrm{kg}^{-1}\right)$ than all other varieties (Fig. 2c). The DON content in grains was mainly influenced by the environment and to a lesser extent by the variety (Table 3 ). Nevertheless, not all varieties performed similarly in all environments, as indicated by significant GxE interactions $(P<0.05)$ (Table 3). Indeed, higher DON contaminations in "Cassia" and in "Fridericus" were observed in grains from Reckenholz 2014 than from Changins 2014. The opposite was observed for "Semper" with highest contamination measured in Changins 2014. Overall, the DON content in grains was influenced by the barley genotype as well as by the interaction of the genotype and the environment (Table 3 ).

\section{Interactions between resistance traits}

Disease incidence and disease severity were highly correlated $(P<0.001)$ (Table 4$)$. A significant $(P<0.001)$ correlation was also found between the proportion of grains colonised by FG and the reduction of TKW due to artificial inoculation. However, DON content in grains was neither related with colonisation nor with the reduction of TKW. The severity and the incidence of symptoms on the spikes were neither correlated with TKW reduction nor with the proportion of FG colonised grains but with the DON content.

The interactions between grain resistance factors were studied with a Principal Component Analysis (PCA) (Fig. 3). Here again, the PCA showed the positive link between the colonisation of grains and the reduction of TKW, whereas the DON content in the grains was clearly not linked with colonisation and

Table 4 Pearson correlation coefficients between observed spikes and grains at four field tests

$$
\text { Disease incidence }^{\mathrm{a}} \text { Disease severity }^{\mathrm{b}} \text { ) Proportion of Fusarium } \quad \text { DON }^{\mathrm{c}} \text { content }
$$
graminearum colonised grains in grains

\begin{tabular}{|c|c|c|c|c|}
\hline Disease severity (\% spikelets with symptoms) & $0.85 * * *$ & & & \\
\hline $\begin{array}{l}\text { Proportion of Fusariumgraminearum } \\
\text { colonised grains }\end{array}$ & ns & ns & & \\
\hline DON content in grains & $0.48 * * *$ & $0.42 * * *$ & Ns & \\
\hline Reduction of TKW ${ }^{\mathrm{d}}$ & $\mathrm{ns}$ & ns & $0.62 * * *$ & ns \\
\hline
\end{tabular}

Significant level: ***: $P<0.001$, ns: not significant

${ }^{\mathrm{a}}$ Number of spikes with symptoms; ${ }^{\mathrm{b}}$ Percent spikelets with symptoms; ${ }^{\mathrm{c}}$ DON, deoxynivalenol; ${ }^{\mathrm{d}}$ TKW, thousand kernel weight 
Fig. 3 Biplot representation of a Principal Component Analysis (PCA) of grain resistance against accumulation of DON

(deoxynivalenol), grain colonisation (FCG) and reduction of thousand kernel weight (TKW) for six varieties in four environments. Each pair

"Genotype:Environment" is one individual point in the PCA. Individuals have been classed into three resistance groups (A-C) using a hierarchical cluster analysis. C: Cassia, F: Fridericus, H: Hobbit, L: Landi, S: Semper, W: Waxyma; CH14: Changins 2014, RE14: Reckenholz 2014, RE15: Reckenholz 2015, VO14: Vouvry 2014

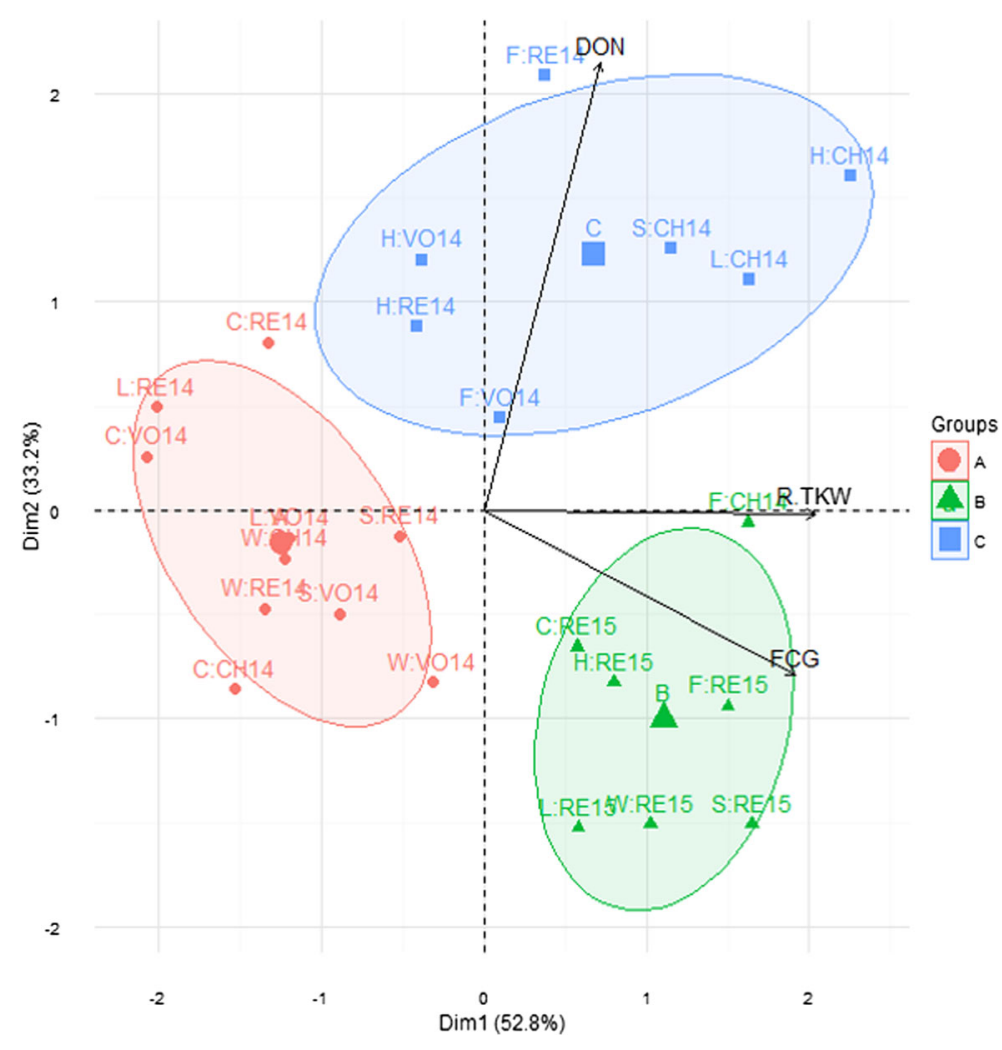

TKW reductions. The hierarchical cluster analysis identified three distinct clusters: cluster A includes low DON content, low TKW reductions and low proportion of grains colonised by FG. Cluster B is composed of individuals affected by the reduction of TKW and with a high proportion of FG colonised grains but low DON contaminations. Cluster $\mathrm{C}$ gathers individuals highly contaminated with DON, along with a wide range of TKW reduction and proportion of FG colonised grains. Overall, cluster A consisted mainly of "Waxyma" and "Cassia", regardless of the environment. Cluster B gathered most of the individuals from Reckenholz 2015, and cluster $\mathrm{C}$ contained all other remaining variety $\mathrm{x}$ environment combinations (Fig. 3).

\section{Impact of the Fusarium infection on the $\beta$-glucan content in grains}

In our data set, grains contained between $3.1 \%$ and $6.8 \%$ of $\beta$-glucan in dry weight. The highest contents were measured in "Waxyma" grains from non-inoculated plots (on average $6.5 \%$ over all environments), and the lowest contents in "Landi" grains $(4.0 \%$ over all environments). Generally, higher $\beta$-glucan content was measured in grains from Reckenholz in 2014 and 2015 (4.9\% and $4.8 \%$, respectively over all genotypes) compared with grains from Vouvry 2014 (4.5\%). Content in grains from "Cassia" varied between the different environments from $4.4 \%$ in Changins 2014 to $5.1 \%$ in Reckenholz 2014; all other varieties showed stable contents across environments (data not shown). It resulted in weak but significant GxE interactions (Table 5).

Artificial inoculations significantly impacted the $\beta$ glucan content in grains $(P<0.01)$ (Table 5). By comparison, $\beta$-glucan contents were generally lower by $10 \%$ in grains from inoculated plants than in grains from control plots (Fig. 4). The decrease was the same in all varieties and in all environments (Fig. 4).

Link between $\beta$-glucan content and grain resistance traits

The comparison of the $\beta$-glucan content in infected grains between the three grain resistance groups previously defined by hierarchical clustering revealed significant differences $(P<0.05)$. While grains in cluster $\mathrm{A}$ (resistance to FG infection and DON contamination) contained on average $4.8 \% \beta$-glucan, grains from 
Table 5 Analysis of variance of $\beta$-glucan content in grains of 6 barley varieties, from four different field sites, inoculated or not with Fusarium graminearum

\begin{tabular}{lll}
\hline Source of variation & \multicolumn{2}{l}{$\beta$-glucan content $(\%)$} \\
\cline { 2 - 3 } & $\begin{array}{l}\text { Sum of } \\
\text { Square }\end{array}$ & $\begin{array}{c}\text { Mean } \\
\text { Square }\end{array}$ \\
\hline Environment & 3.2 & $1.1 *$ \\
Error (a) & 0.9 & 0.2 \\
Inoculation & 7.6 & $7.6 * *$ \\
Environment x Inoculation & 2.3 & 0.8 \\
Error (b) & 3.0 & 0.4 \\
Genotype & 48.8 & $9.8 * * *$ \\
Genotype x Environment & 6.2 & $0.4 *$ \\
Genotype x Inoculation & 1.0 & 0.2 \\
Genotype x Environment x Inoculation & 4.0 & 0.3 \\
Error (c) & 16.3 & 0.2 \\
\hline
\end{tabular}

Significance: $* * *: P<0.001, * *: P<0.01, *: P<0.05$

cluster C (grains accumulating DON) contained significantly less $\beta$-glucan (average of $4.2 \%$ ) (Fig. 5). The grains of cluster B (elevated proportion of colonized grains and reduced TKW) had an intermediate content (4.5\%). A correlation analysis (Pearson correlation coefficient: $0.29, P<0.01)$ confirmed the significant inverse relationship between DON accumulation and $\beta$-glucan content.

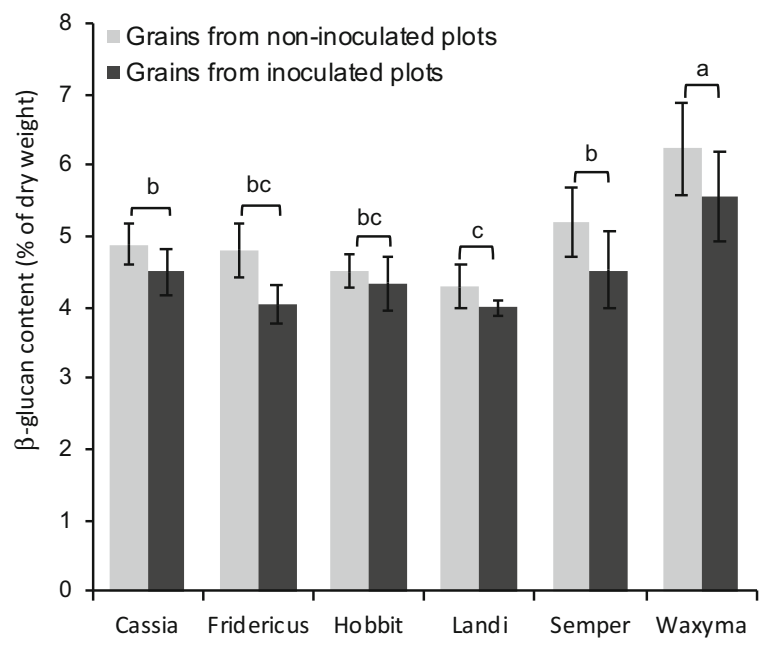

Fig. 4 Comparison of $\beta$-glucan contents in barley grains from inoculated and non-inoculated plots, pooled over 4 environments. Black and grey bars represent average $\beta$-glucan content in dry weight of grains. Error bars represent the standard error of the means. Different letters indicate significant differences between varieties over all environments in inoculated and control samples $(P<0.05)$
The concentration of $\beta$-glucan was not linked with any other grain resistance trait (data not shown).

\section{Discussion}

In the current study, the resistance of six barley varieties against infection with FG was investigated under different field conditions. Besides the symptoms on the spikes, a particular focus was the symptoms of the grains, the accumulation of the mycotoxin deoxynivalol and variations of the $\beta$-glucan content. The severity of symptoms on the spike differed between the varieties and between the environments. Generally, varieties with a higher spike resistance showed reduced accumulation of the mycotoxin DON. Negative correlations between spike resistance and toxin accumulation have also been reported by other authors (e.g. Tekauz et al. 2000; Choo et al. 2004; Berger et al. 2014; He et al. 2015). Yet, the present results show that DON content is not linked with the colonization of the grain by FG. High DON

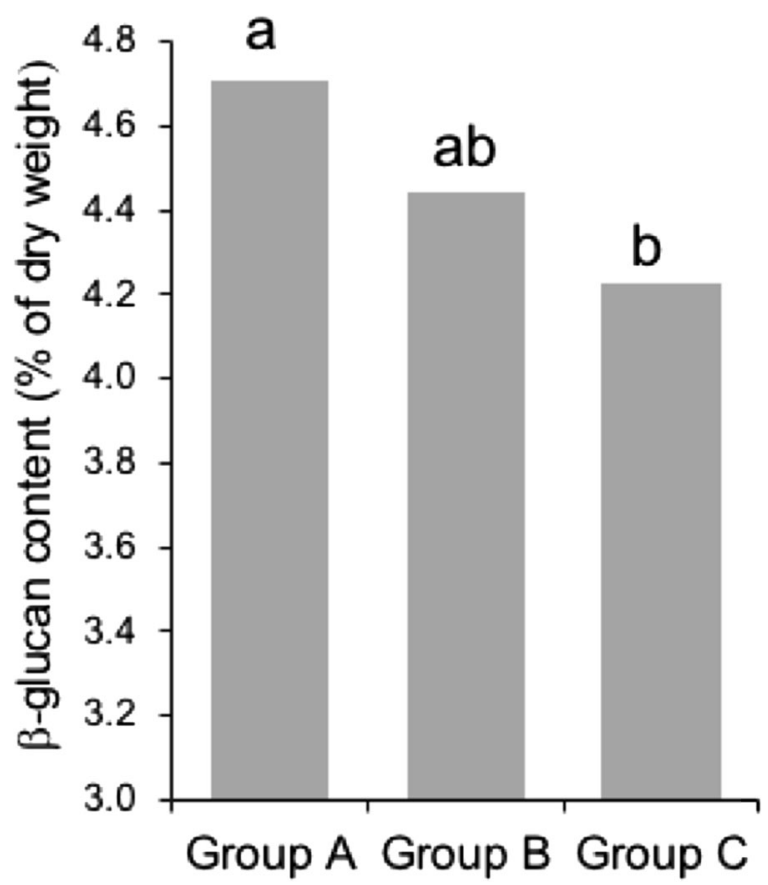

Fig. 5 The average $\beta$-glucan content in barley grains within the three resistance groups. Group $\mathrm{A}=$ grains with a general high resistance level, Group B = grains susceptible to Fusarium colonization and reduction of grain filling, Group $\mathrm{C}=$ grains generally susceptible, with a high DON accumulation. Different letters indicate significant differences according to a Tukey test with $\alpha=0.05$ 
contamination but a weak grain colonisation was found in all samples from inoculated plots in Vouvry 2014, where conditions after anthesis were quite humid. In contrast, in Reckenholz in 2015, where elevated temperatures and low precipitations were registered, we found a high proportion of colonised grains but only low symptoms on the spikes and low accumulation of DON in the grains from inoculated plots. In Vouvry in 2014, characterized by elevated rainfalls and high humidity between flowering and grain maturity, elevated DON content was found despite a moderate symptom level on the spike. This supports the important role of environmental conditions on symptoms development and DON accumulation in barley and confirms findings of other authors (Tekauz et al. 2000; Bai and Shaner 2004; Bernhoft et al. 2012). In practical terms, similar to wheat and triticale, the absence of symptoms on the spike is not a reliable indicator of low mycotoxin accumulation in the grain (Arseniuk et al. 1999; Mesterházy 2002). Arguably, the different genetic basis for spike resistance and for DON accumulation in the grain leads to the differential reaction between spike and grain (Massman et al. 2011). In the following we aim to accurately phenotype the infection induced symptoms on the grains of the six barley varieties.

Therefore, we expected to observe typical symptoms of F.graminearum on the grains such as the presence of scabby grains, pinkish discolouration, or grain deformation as described by McMullen et al. (1997) and He et al. (2015). None of these symptoms were found in our samples, besides the presence of black perithecia that we attributed to Fusarium. Yet, the colonization of the FG inoculum on the grain proves the presence of the pathogen on the grain. It is conceivable, that the elevated disease pressure and conducive meteorological conditions allowed the development of the typical symptoms on the grains in these studies. Indeed, Berger et al. (2014) and He et al. (2015) rated pinkish discolouration in grains from intensively irrigated fields and inoculated with a highly aggressive FG isolate.

The FG infection caused significant reduction of the TKW indicating a disruption in grain filling that impacts grain morphology and shape. The quantification of $\beta$-glucan in the grains revealed a general decrease by $10 \%$ in grains from inoculated plots compared to grains from non-inoculated plots, regardless the variety and the environment. The lower $\beta$-glucan content in infected grains might be attributed on the one hand to the activity of fungal $\beta$ - glucanases and other cell-wall degrading enzymes of Fusarium pathogens (Schwarz et al. 2002; Wang et al. 2005; Oliveira et al. 2012a, b). On the other hand, the reduced supply of sugars and other nutrients can lead to a reduced synthesis of $\beta$-glucan in the developing grain (Fincher 1975; Becker et al. 1995; Wilson et al. 2012). In conclusion, our analyses demonstrated that FG colonises barley grains and by this synthesizing mycotoxins and causing the reduction of the grain size and shape as well as reducing the content in $\beta$-glucan.

The present trials show significant differences of the symptoms of spike and grain between barley genotypes and environmental conditions. Strong interactions between the genotypes and the environments indicate a weak stability of barley resistances traits of spike and grains previously mentioned in genetic studies (Capettini et al. 2003; De la Pena et al. 1999). In our field analyses, we observed that the interactions of the genotype with the environment determine, to the same extent, the phenotypic variation of symptoms on the spike, the DON content and the reduction of grain filling. Heritability of resistance against FG infection is therefore lower than that in wheat, confirming the findings of other authors (Bai et al. 2000; Urrea et al. 2002; Capettini et al. 2003). Consequently, in practical breeding, the expected genetic of FHB resistance is rather weak.

Nevertheless, among the varieties, we found differences in resistance against all facets of FHB. The two-row variety "Cassia" showed the highest resistance with respect to spike symptoms, FG grain colonisation and TKW reduction. "Waxyma" was the most resistant variety with respect to DON accumulation and second to "Cassia" in all other categories. In contrast to six-row varieties, two-row spikes may impede the external propagation of the pathogen from one spikelet to the other (Choo et al. 2004; Langevin et al. 2004), Even though in "Cassia" and "Waxyma" both spike and grain resistances are present, results of the less resistant genotypes show that the two resistance types are acting independently. The degree of colonisation of the grain was linked to the reduction of grain filling but not linked with accumulation of DON. It is known for barley, that the colonisation of the grain is independent from the accumulation of trichothecenes mycotoxins (Langevin et al. 2004; Maier et al. 2006). Yet, the degree of abundance of the FG 
pathogen may impair the grain filling processes. No resistance was found in any of the six barley varieties to prevent $\beta$-glucan degradations caused by the infection. Overall, our resistance analyses suggest the existence of two distinct resistance mechanisms in the grain, namely: (i) the continuity of grain filling and reduced colonization and (ii) the inhibition of mycotoxin accumulation. Type IV resistance (tolerance of grains to FHB) seems to be directly linked to type III resistance (resistance to kernel infection). Meanwhile, type $\mathrm{V}$ resistance (resistance against trichothecenes accumulation) appears to be independent from all other resistance types.

Interestingly, varieties with the highest $\beta$-glucan content (Fig. 3, cluster A) displayed the lowest DON content. Arguably, the nature of interaction between the $\beta$ glucan content and the contamination with DON and its role in resistance is source of debate. On the one hand, a higher $\beta$-glucan content might enhance the resistance against DON accumulation thus contributing to type $\mathrm{V}$ resistance by antioxidant activity of $\beta$-glucan (Kofuji et al. 2012). Indeed, several studies demonstrated the inhibitive potential of natural antioxidant compounds on the production of mycotoxins (Boutigny et al. 2010; Pani et al. 2014; Zhou et al. 2007). On the other hand, a lower $\beta$-glucan content may allow the accumulation of DON. Indeed, it has been demonstrated that $\beta$-glucan is able to bind several Fusarium toxins in vitro (Yiannikouris et al. 2004, 2006). Previous findings recommend it as a potential detoxifiant of food products contaminated with Fusarium toxins (Meca et al. 2012; El-Naggar and Thabbit 2014). In any case, cultivating barley varieties with high $\beta$-glucan contents can be recommended to serve two purposes at the same time: to reduce the risk of mycotoxin contaminated grains and to further promote the production of health promoting food (Ames and Rhymer 2008).

Acknowledgments This research was funded by the Swiss National Research Program 69 "Healthy Nutrition and Sustainable Food Production" (contract: SNF $145210 / 1$ ). We thank Stefan Kellenberger for his highly valuable assistance in field experiments, and Florian Combremont and Caroline Litzistorf for their help with laboratory work.

Compliance with ethical standards The manuscript is original. No part of the manuscript has been published before nor is any part of it under consideration for publication at another journal.

Conflict of interest The authors declare they have no conflict of interest. All authors fully agree for submission of the manuscript.
Open Access This article is distributed under the terms of the Creative Commons Attribution 4.0 International License (http:// creativecommons.org/licenses/by/4.0/), which permits unrestricted use, distribution, and reproduction in any medium, provided you give appropriate credit to the original author(s) and the source, provide a link to the Creative Commons license, and indicate if changes were made.

\section{References}

Ames, N. P., \& Rhymer, C. R. (2008). Issues Surrounding Health Claims for Barley 1-2. The Journal of Nutrition, 138, 1237 1243.

Arseniuk, E., Foremska, E., \& Chełkowski, J. (1999). Fusarium head blight reactions and accumulation of deoxynivalenol (DON) and some of its derivatives in kernels of wheat, triticale and rye. Journal of Phytopathology, 147(10), 577590.

Bai, G. H., Shaner, G., \& Ohm, H. (2000). Inheritance of resistance to Fusarium graminearum in wheat. Theoretical and Applied Genetics, 100, 1-8.

Bai, G., \& Shaner, G. (2004). Management and resistance in wheat and barley to Fusarium head blight. Annual Review of Phytopathology, 42, 135-161. https://doi.org/10.1146 /annurev.phyto.42.040803.140340.

Becker, M., Vincent, C., \& Reid, J. S. G. (1995). Biosynthesis of $(1,3)(1,4)$-beta-glucan and $(1,3)$-beta-glucan in barley (Hordeum vulgare L.). Planta, 10, 331-338.

Berger, G., Green, A., Khatibi, P., Brooks, W., Rosso, L., Liu, S., et al. (2014). Characterization of Fusarium head blight resistance and deoxynivalenol accumulation in hulled and hulless winter barley. Plant Disease, 98, 599-606.

Bernhoft, A., Torp, M., Clasen, P. E., Løes, A. K., \& Kristoffersen, A. B. (2012). Influence of agronomic and climatic factors on Fusarium infestation and mycotoxin contamination of cereals in Norway. Food Additives \& Contaminants: Part A, 29(7), 1129-1140. https://doi.org/10.1080 /19440049.2012.672476.

Boutigny, A.-L., Richard-Forget, F., \& Barreau, C. (2008). Natural mechanisms for cereal resistance to the accumulation of Fusarium trichothecenes. European Journal of Plant Pathology, 121(4), 411-423. https://doi.org/10.1007 /s10658-007-9266-x.

Boutigny, A.-L., Atanasova-Pénichon, V., Benet, M., Barreau, C., \& Richard-Forget, F. (2010). Natural phenolic acids from wheat bran inhibit Fusarium culmorum trichothecene biosynthesis in vitro by repressing Tri gene expression. European Journal of Plant Pathology, 127(2), 275-286. https://doi.org/10.1007/s10658-010-9592-2.

Brennan, J. M., Egan, D., Cooke, B. M., Doohan, F. M., Puri, K. D., Zhong, S., ... Forrer, H. R. (2005). Effect of temperature on head blight of wheat caused by Fusarium culmorum and F. graminearum. Plant Pathology, 54(2), 156-160. https://doi.org/10.1111/j.1365-3059.2005.01157.x

Buerstmayr, H., Legzdina, L., Steiner, B., \& Lemmens, M. (2004). Variation for resistance to Fusarium head blight in spring barley. Euphytica, 137(3), 279-290.

Capettini, F., Rasmusson, D. C., Dill-Macky, R., Schiefelbein, E., \& Elakkad, A. (2003). Inheritance of resistance to Fusarium 
head blight in four populations of Barley. Crop Science, 43(6), 1960-1966. https://doi.org/10.2135 /cropsci2003.1960.

Chełkowski, J., Wiśniewska, H., Adamski, T., Goliński, P., Kaczmarek, Z., Kostecki, M., et al. (2000). Effects of Fusarium culmorum head blight on mycotoxin accumulation and yield traits in barley doubled haploids. Journal of Phytopathology, 148, 541-545.

Choo, T., Vigier, B., Shen, Q., Martin, R., Ho, K., \& Savard, M. (2004). Barley traits associated with resistance to fusarium head blight and deoxynivalenol accumulation. Phytopathology, 94(10), 1145-1150. https://doi.org/10.1094 /PHYR0.2004.94.10.1145.

Courvoisier, N., Levi Häner, L., Bertossa, M., Thévoz, E., Anders, M., Stoll, T., Weisflog, T., Dugon, J., Graf, B., \& Hofer, M. (2017). Liste recommandée des variétés de céréales pour la récolte 2018. Available at: http://www.swissgranum.ch/88-2Listes-recommandes.html [in French]

D'Mello, J. F. P., Placinta, C. M., \& Macdonald, A. M. C. (1999). Fusarium mycotoxins: a review of global implication for animal health, welfare and productivity. Animal Feed Science and Technology, 80(3), 183-205. https://doi. org/10.1016/S0377-8401(99)00059-0.

De la Pena, R. C., Smith, K. P., Capettini, F., Muehlbauer, G. J., Gallo-Meagher, M., Dill-Macky, R., Somers, D. A., \& Rasmusson, D. C. (1999). Quantitative trait loci associated with resistance to Fusarium head blight and kernel discoloration in barley. Theoretical and Applied Genetics, 99(3), 561-569.

De Mendiburu F., 2015, agricolae: Statistical Procedures for Agricultural Research, Versio1.2-4, http://tarwi.lamolina. edu.pe/ fmendiburu

Dersjant-li, Y., Verstegen, M. W. A., \& Gerrits, W. J. J. (2003). The impact of low concentrations of aflatoxin, deoxynivalenol or fumonisin in diets on growing pigs and poultry. Nutrition Research Reviews, 16(2), 223-239.

El-Naggar, M. A., \& Thabbit, T. M. (2014). Evaluation of $\beta$-Dglucan biopolymer as a novel mycotoxin binder for fumonisin and deoxynivalenol in soybeen feed. Foodborne Pathogens and Disease, 11(6), 433-438.

European Food Safety Authority. (2011). Scientific Opinion on the substantiation of health claims related to beta-glucans from oats and barley and maintenance of normal blood LDLcholesterol concentrations (ID 1236, 1299), increase in satiety leading to a reduction in energy intake (ID 851, 852. EFSA Journal, 9(6).

FDA. (1997). 21 CFR Part 101. Food labeling, health claims: soluble dietary fiber from certain foods and coronary heart disease. Federal Register, 62(15), 3584-3601.

FDA. (2005). 21 CFR Part 101. Food labeling, health claims: soluble dietary fiber from certain foods and coronary heart disease. Federal Register, 62(246), 76150-76162.

Fincher, G. B. (1975). Morphology and chemical composition of barley endosperm cell walls. J. Inst. Brew, 81, 116-122.

Foroud, N. A., \& Eudes, F. (2009). Trichothecenes in cereal grains. International Journal of Molecular Sciences, 10, 147-173.

Frutos, E., Galindo, M. P., \& Leiva, V. (2014). An interactive biplot implementation in $\mathrm{R}$ for modeling genotype-byenvironment interaction. Stochastic Environmental Research and Risk Assessment, 28(7), 1629-1641.
Häller Gärtner, B., Munich, M., Kleijer, G., \& Mascher, F. (2008). Characterisation of kernel resistance against Fusarium infection in spring wheat by baking quality and mycotoxin assessments. European Journal of Plant Pathology, 120, 61-68. https://doi.org/10.1007/s10658-007-9198-5.

He, X., Osman, M., Helm, J., Capettini, F., \& Singh, P. K. (2015). Evaluation of Canadian barley breeding lines for Fusarium head blight resistance. Canadian Journal of Plant Science, 95(5), 923-925.

Ioos, R., Belhadj, A., \& Menez, M. (2004). Occurrence and distribution of Microdochium nivale and Fusarium Species isolated from barley, durum and soft wheat grains in France from 2000 to 2002. Mycopathologia, 158, 1-8. https://doi. org/10.1007/s11046-004-2228-3.

Izydorczyk, M. S., Storsley, J., Labossiere, D., MacGregor, A. W., \& Rossnagel, B. G. (2000). Variation in total and soluble $\beta$ glucan content in hulless barley: effects of thermal, physical, and enzymic treatments. Food Chemistry, 48(4), 982-989.

Jansen, C., von Wettstein, D., Schäfer, W., Kogel, K.-H., Felk, A., \& Maier, F. J. (2005). Infection patterns in barley and wheat spikes inoculated with wild-type and trichodiene synthase gene disrupted Fusarium graminearum. PNAS, 102, 16892-16897.

Kassambara, A. \& Mundt, F. (2017). factoextra: Extract and Visualize the Results Multivariate Data Analyses. https:/CRAN.R-project.org/package=factoextra.

Kofuji, K., Aoki, A., Tsubaki, K., Konishi, M., İsobe, T., \& Murata, Y. (2012). Antioxidant Activity of $\beta$-Glucan. ISRN Pharmaceutics, 2012(125864).

Kushiro, M. (2008). Effects of milling and cooking processes on the deoxynivalenol content in wheat. International Journal of Molecular Sciences, 9(11), 2127-2145.

Langevin, F., Eudes, F., \& Comeau, A. (2004). Effect of trichothecenes produced by Fusarium graminearum during Fusarium head blight development in six cereal species. European Journal of Plant Pathology, 110, 735-746.

Lattanzio, V., Lattanzio, V. M. T., Cardinali, A., \& Amendola, V. (2006). Role of phenolics in the resistance mechanisms of plants against fungal pathogens and insects. (F. Imperato, Ed.) (Vol. 661).

Le, S., Josse, J., \& Husson, F. (2008). FactoMineR: An R Package for Multivariate Analysis. Journal of Statistical Software, 25(1), 1-18.

Leslie, J. F., \& Summerell, B. A. (2006). The Fusarium Laboratory Manual. Blackwell Publishing.

Maier, F. J., Miedaner, T., Hadeler, B., Felk, A., Salomon, S., Lemmens, M., et al. (2006). Involvement of trichothecenes in fusarioses of wheat, barley and maize evaluated by gene disruption of the trichodiene synthase (Tri5) gene in three field isolates of different chemotype and virulence. Molecular Plant Pathology, 7, 449-461. https://doi. org/10.1111/j.1364-3703.2006.00351.x.

Malachova, A., Varga, E., Schwartz, H., Krska, R., \& Bertillier, F. (2012). Development, validation and application of an LCMS/MS based method for the determination of deoxynivalenol and its conjugates in different types of beer. World Mycotoxin Journal, 5(3), 261-270. https://doi. org/10.3920/WMJ2012.1425.

Martin, C., Schöneberg, T., Vogelgsang, S., Vincenti, J., Bertossa, M., Mauch-mani, B., \& Mascher, F. (2017). Factors of wheat grain resistance to Fusarium head blight. Phytopathologia 
Mediterranea, 56, 154-166. https://doi.org/10.14601 /Phytopathol.

Mascher, F., Michel, V., \& Browne, R. (2005). Sélection de variétés de blé et de triticale résistantes à la fusariose sur épi. Revue Suisse D’agriculture, 37(5), 189-194. Retrieved from ht t p : / / cat.inist.fr/? a Modele= afficheN\&cpsidt=17127342 [in French]

Massman, J., Cooper, B., Horsley, R., Neate, S., Dill-Macky, R., Chao, S., Dong, Y., Schwarz, P., Muehlbauer, G. J., \& Smith, K. P. (2011). Genome-wide association mapping of Fusarium head blight resistance in contemporary barley breeding germplasm. Molecular breeding, 27(4), 439-454.

McMullen, M., Jones, R., Gallenberg, D., America, S., Mcmullen, M., \& Jones, R. (1997). Scab of wheat and barley: a reemerging disease of devastive impact. Plant Disease, 81(12), 1340-1348.

Meca, G., Meneghelli, G., Ritieni, A., Manes, J., \& Font, G. (2012). Influence of different soluble dietary fibers on the bioaccessibility of the minor Fusarium mycotoxin beauvericin. Food and chemical toxicology, 50(5), 13621368.

Mesterházy, Á., Bartók, T., Mirocha, C. G., \& Komoroczy, R. (1999). Nature of wheat resistance to Fusarium head blight and the role of deoxynivalenol for breeding. Plant Breeding, $118,97-110$.

Mesterházy, Á. (2002). Role of deoxynivalenol in aggressiveness of Fusarium graminearum and F. culmorum and in resistance to Fusarium head blight. European Journal of Plant Pathology, 108, 675-684.

Musa, T., Hecker, A., Vogelgsang, S., \& Forrer, H. R. (2007). Forecasting of Fusarium head blight and deoxynivalenol content in winter wheat with FusaProg *. Bulletin OEPP/EPPO, 283-289.

Nielsen, L. K., Cook, D. J., Edwards, S. G., \& Ray, R. V. (2014). The prevalence and impact of Fusarium head blight pathogens and mycotoxins on malting barley quality in UK. European Food Research and Technology, 179, 38-49. https://doi.org/10.1016/j.ijfoodmicro.2014.03.023.

Oliveira, P. M., Mauch, A., Jacob, F., \& Arendt, E. K. (2012a). Impact of Fusarium culmorum-infected barley malt grains on brewing and beer quality. Journal of the American Society of Brewing Chemists, 70(3), 186-194.

Oliveira, P. M., Mauch, A., Jacob, F., Waters, D. M., \& Arendt, E. K. (2012b). Fundamental study on the influence of Fusarium infection on quality and ultrastructure of barley malt. International journal of food microbiology, 156(1), 32-43.

Oliveira, P. M., Waters, D. M., \& Arendt, E. K. (2013). The impact of Fusarium culmorum infection on the protein fractions of raw barley and malted grains. Applied Microbiology Biotechnology, 97(5), 2053-2065 https://doi.org/10.1007 /s00253-013-4696-1.

Pani, G., Scherm, B., Azara, E., Balmas, V., Jahanshiri, Z., Carta, P., et al. (2014). Natural and Natural-like Phenolic Inhibitors of Type B Trichothecene in Vitro Production by the Wheat ( Triticum sp.) Pathogen Fusarium culmorum. Journal of Agricultural and Food Chemistry, 62, 4969-4978.

R Core Team. (2015). R: A language and Environment for Statistical Computing. Vienna, Austria: R Foundation for Statistical Computing http://www.R-project.org.
Schöneberg, T., Martin, C., Wettstein, F. E., Bucheli, T. D., Mascher, F., Bertossa, M., et al. (2016). Fusarium and mycotoxin spectra in Swiss barley are affected by various cropping techniques. Food Additives and Contaminants, 33(10), 1608-1619. https://doi.org/10.1080 /19440049.2016.1219071.

Schroeder, H. W., \& Christensen, J. J. (1963). Factors affecting resistance of wheat to scab caused by Gibberella zeae. Phytopathology, 53(7,1), 831-838.

Schwarz, P. B., Jones, B. L., \& Steffensen, B. (2002). Enzymes associated with Fusarium infection of barley. Journal of the American Society of Brewing Chemists, 60(3), 130-134.

Urrea, C. A., Horsley, R. D., Steffenson, B. J., \& Schwarz, P. B. (2002). Heritability of Fusarium head blight resistance and deoxynivalenol accumulation from barley accession CIho 4196. Crop science, 42(5), 1404-1408.

Tekauz, A., McCallum, B., \& Gilbert, J. (2000). Fusarium head blight of barley in western Canada. Canadian Journal of Plant Pathology, 22(1), 9-16. https://doi.org/10.1080 /07060660009501156.

Vogelgsang, S., Sulyok, M., Hecker, A., Jenny, E., Krska, R., Schuhmacher, R., \& Forrer, H. R. (2008). Toxigenicity and pathogenicity of Fusarium poae and Fusarium avenaceum on wheat. European Journal of Plant Pathology, 122(2), 265-276.

Wang, J., Wieser, H., Pawelzik, E., Weinert, J., Keutgen, A. J., \& Wolf, G. A. (2005). Impact of the fungal protease produced by Fusarium culmorum on the protein quality and breadmaking properties of winter wheat. European Food Research and Technology, 220(5-6), 552-559.

Wilson, S. M., Burton, R. A., Collins, H. M., Doblin, M. S., Pettolino, F. A., Shirley, N., Fincher, G. B., \& Bacic, A. (2012). Pattern of deposition of cell wall polysaccharides and transcript abundance of related cell wall synthesis genes during differentiation in barley endosperm. Plant Physiology, 159(2), 655-670.

Wood, P. J. (2007). Cereal $\beta$-glucans in diet and health. Journal of Cereal Science, 46(3), 230-238.

$\mathrm{Xu}, \mathrm{X}$. (2003). Effects of environmental conditions on the development of Fusarium ear blight. European Journal of Plant Pathology, 109(7), 683-689.

Yiannikouris, A., Francois, J., Poughon, L., Dussap, C. G., Bertin, G., Jeminet, G., \& Jouany, J. P. (2004). Adsorption of zearalenone by $\beta$-D-glucans in the Saccharomyces cerevisiae cell wall. Journal of food protection, 67(6), 1195-1200.

Yiannikouris, A., André, G., Poughon, L., François, J., Dussap, C. G., Jeminet, G., Bertin, G., \& Jouany, J. P. (2006). Chemical and conformational study of the interactions involved in mycotoxin complexation with $\beta$-D-glucans. Biomacromolecules, 7(4), 1147-1155.

Zhang, G., Junmei, W., \& Jinxin, C. (2002). Analysis of b -glucan content in barley cultivars from different locations of China. Food Chemistry, 79, 251-254.

Zhou, K., Hao, J., Griffey, C., Chung, H., O’Keefe, S. F., Chen, J., \& Hogan, S. (2007). Antioxidant properties of Fusarium head blight-resistant and -susceptible soft red winter wheat grains grown in Virginia. Journal of Agricultural and Food Chemistry, 55(9), 3729-3736. https://doi.org/10.1021 /jf070147a. 